Article

\title{
Luffa Pretreated by Plasma Oxidation and Acidity to Be Used as Cellulose Films
}

\author{
Ying Wang ${ }^{1, *}$, Zhao-xuan Ding ${ }^{1}$, Yan-hui Zhang ${ }^{2}$, Chun-yan Wei ${ }^{1}$ and Zi-chang Xie ${ }^{1}$ \\ 1 School of Textile and Material Engineering, Dalian Polytechnic University, Dalian 116034, China; \\ dingzhaoxuan2@126.com (Z.-x.D.); weicy@dlpu.edu.cn (C.-y.W.); xie_zc1225@126.com (Z.-c.X.) \\ 2 Shanghai Textile Research Institute Co., Ltd., Shanghai 200082, China; zhangyanhui7712@163.com \\ * Correspondence: wangying@dlpu.edu.cn; Tel.: +86-041-186-318-763
}

Received: 27 November 2018; Accepted: 23 December 2018; Published: 27 December 2018

\begin{abstract}
Cellulose is the most abundant natural polymer on earth. With the increasing shortage of oil resources, people have been focusing more on producing natural cellulose. In this study, guaiacol was used as the model compound to investigate the degradation of lignin in luffa. A new cellulose material was extracted from natural luffa by a pretreatment based on the oxidation and acidity of glow discharge plasma in water. The produced luffa cellulose was dissolved in anhydrous phosphoric/polyphosphoric acid (aPPAC) solvent to prepare cellulose film. Results showed that the reactive species of $\mathrm{OH} \cdot, \mathrm{HO}_{2} \cdot$ and $\mathrm{H}_{3} \mathrm{O}^{+}$were produced during the plasma discharge of water. The free radicals $\cdot \mathrm{OH}$ were useful in eliminating lignin by the destruction of aromatic structure, whereas $\mathrm{H}_{3} \mathrm{O}^{+}$in eliminating hemicellulose in the luffa raw material. At the conditions of luffa powder concentration of $9.26 \mathrm{~g} / \mathrm{L}$, discharge time of $20 \mathrm{~min}$, and plasma power of $100 \mathrm{~W}$, the cellulose component was increased to $81.2 \%$. After $25 \mathrm{~min}$, the luffa cellulose was completely dissolved in the aPPAC solvent at $0-5{ }^{\circ} \mathrm{C}$. Thus, a regenerated cellulose film of cellulose II was prepared. The aPPAC solvent was a good non-derivatizing solvent for the luffa cellulose. The regenerated film exhibited good mechanical properties, wettability and a compact structure. Therefore, plasma pretreatment was an environmentally friendly and high-efficiency method for luffa degumming. The luffa cellulose can be well used in dissolution and regeneration in films.
\end{abstract}

Keywords: luffa cellulose; dissolution; film; plasma treatment

\section{Introduction}

Cellulose is the most abundant natural polymer on earth. With the increasing shortage of oil resources, people focus more on developing natural cellulose existing in plants, minerals, sea elements, etc. Over the last few years, a number of researchers were involved in investigating the exploitation of natural cellulose from plant fibers due to their affordability and recyclability. Some of these plant fibers have been extensively investigated and widely used as materials in textile or chemical fiber industries (e.g., bamboo and hemp). However, many fibers with very high potential cellulose components (e.g., piassava, caroa, and luffa (sponge gourd), among many others) have not been fully explored yet.

Luffa is a vascular bundle of dried ripe luffa fruits that have a three-dimensional fiber layer and a unique porous physical structure [1]. Nowadays, it is widely employed as filter and adsorption material for dye and metal ions [2,3]. For other industrial applications, luffa is also used as a matrix in reinforcing composite materials. Meanwhile, luffa powder was used for medical purposes to improve skin quality and decrease blood lipid level in ancient China. According to the Compendium of Materia Medica records, the juice of luffa was used as a natural remedy for jaundice. Luffa has also been utilized as a bathroom or kitchen accessory after being processed. However, aside from these reports, few previous studies were conducted on luffa cellulose for regeneration purposes in producing films. 
The typical mass percentages of natural luffa are $60-65 \%$ cellulose, $15-20 \%$ hemi-cellulose, and $10-15 \%$ lignin. Natural luffa fibers can be regarded as naturally occurring composites consisting mainly of cellulose fibrils embedded in lignin matrix. Apart from rigidity, lignin also provides maximum tensile and strength. However, one of the drawbacks on the applications of luffa is the serious adhesion between lignin and cellulose. The chemical method is effective, particularly in the case of lignin removal by using an alkali hydrogen peroxide solution, and it is widely used in the luffa degumming process [4]. However, this method has many disadvantages, including environmental pollution. Consequently, given increasing green awareness and concern for the environment, an eco-friendly degumming method is being investigated.

The use of low-temperature atmospheric pressure plasma in biology, health care, and medicine elicits an increasing interest and has become one of the main topics of plasma research $[5,6]$. Many experimental studies have been conducted on the production of a large variety of plasma species, such as reactive oxygen species (e.g., $\mathrm{O}, \mathrm{OH} \cdot \mathrm{HO}_{2}$, and $\mathrm{O}_{3}$ ), which are probably the most important species used for cellulose extraction [7]. By controlling the plasma discharge condition, a large variety of hydroxyl free radical $\cdot \mathrm{OH}$ and $\mathrm{H}^{+}$was produced. Free radical $\cdot \mathrm{OH}$ and $\mathrm{HO}_{2}$. are useful in eliminating lignin, whereas $\mathrm{H}^{+}$in eliminates hemicelluloses, pectin, and other non associated substances in the luffa raw material [8]. Therefore, the natural luffa in this study was pretreated by glow discharge plasma in water. A new cellulose material was extracted from a natural luffa. The crystal nature of naturally occurring luffa is known as cellulose I. The final extracted cellulose is easily hydrolyzed by acid to water-soluble sugars. Luffa cellulose derivatives, such as cellulose ether and cellulose ester, are the widely used additives in drugs, architecture, food, petrochemical industry and the like. The low cost and reasonable performance of luffa cellulose, including being antibacterial and biodegradable, can fulfill some of the urgent economic and environment protection interests of the chemical fiber and cellulose film industry.

Solvent plays an important role in the dissolution and regeneration properties of luffa cellulose due to its final application. Many processing methods, such as viscose, $n$-methylmorpholine- $n$-oxid (NMMO) and ionic liquid process, are available to dissolve and regenerate cellulose. The viscose process, using sodium hydroxide as solvent, leads to acritical environmental pollution problem, whereas the NMMO process [9] is very costly. Ionic liquid is a good solvent for cellulose. The dissolution and regeneration in films of luffa in 1-butyl-3-methylimidazolium chloride has been investigated in our previous study [10]. Then in this study, a phosphoric/polyphosphoric acid (PPAC) solvent was prepared by mixing phosphoric acid (PA) and polyphosphoric acid (PPA). The cellulose has been proven to immediately dissolve in the anhydrous PPAC (aPPAC) solvent [11]. It has the following advantages: simple operation, low cost, less time-consuming, and with a low dissolution temperature. Thereafter, the extracted luffa cellulose was dissolved in the aPPAC solvent. The dissolvent process of luffa cellulose in the compound solvent was observed via a polarized optical microscope. The regenerated cellulose film was prepared to maximize the potential applications of natural luffa in cellulose industry. The structure and properties of the luffa regenerated cellulose films were characterized via a scanning electron microscopy (SEM), Fourier transform infrared spectroscopy (FTIR), X-ray diffraction (XRD), mechanical properties, and contact angle measurements. The results were discussed in detail in this paper.

\section{Materials and Methods}

\subsection{Materials}

The dried luffa was purchased from Luohe Commodity Co., Ltd., Luohe, China. The PA, PPA, crystal violet (CV), $n$-butanol and guaiacol were obtained from Tianjin Kemiou Chemical Reagent Co., Ltd., Tianjing, China. 


\subsection{Plasma Treatment}

The CTP1200 plasma treatment equipment was made by Coronalab, Nangjing, China. The reactor is shown in Figure 1. The dielectric barriers of this reactor were quartz glass, with a polar distance of $8 \mathrm{~mm}$. The aqueous solutions (e.g., luffa and guaiacol) were placed into a plasma reactor.

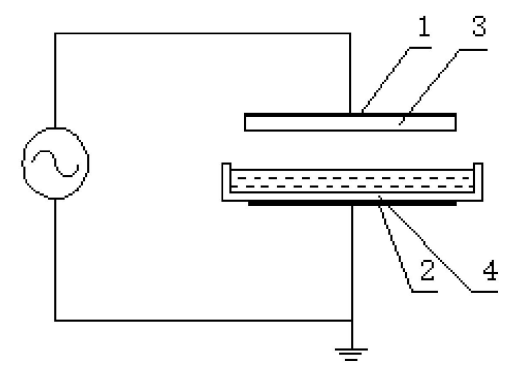

Figure 1. Chart of the plasma reactor: 1 and 2 are electrodes and 3 and 4 are barriers.

\subsection{Evidence of the Radical Produced by Plasma}

To gather the evidence of free radicals produced by plasma in water, the experiment was performed as follows (as listed in Table 1). Before the plasma discharge, the distilled water was placed on the surface of the quartz electrode and treated in the discharge power of $100 \mathrm{~W}$, polar distance of $8 \mathrm{~mm}$, and treatment time of $30 \mathrm{~s}$. After the treatment, the water was quickly removed into a $0.1 \%$ $\mathrm{CV}$ solution. The $\mathrm{CV}$ dye is a radical indicator. Then, a radical scavenger, $n$-butanol, was added. The absorbance of CV solutions was measured using the UV-8000 (Shimadzu Corporation, Tokyo, Japan) ultraviolet visible (UV) spectrophotometer, and the absorbance was obtained.

Table 1. Experiments to determine radicals produced by plasma in water.

\begin{tabular}{ccccc}
\hline No. & $\mathbf{0 . 1} \% \mathbf{C V}(\mathbf{m L})$ & Water $(\mathbf{m L})$ & Plasma Treated Water $(\mathrm{mL})$ & $n$-Butanol $(\mathbf{m L})$ \\
\hline $\mathrm{a}$ & 2 & 2 & 0 & 0 \\
$\mathrm{~b}$ & 2 & 0 & 2 & 0 \\
$\mathrm{c}$ & 2 & 0 & 1.7 & 0.3 \\
\hline
\end{tabular}

\subsection{Drawing the Standard Curve of Guaiacol}

To obtain the degradation condition of lignin, the guaiacol was used as the model compound. Different concentration of guaiacol-water solutions was prepared, and the absorbance of guaiacol solutions was determined using the UV spectrophotometer in the range of $200-500 \mathrm{~nm}$. The standard curve of the guaiacol was drawn with the guaiacol concentration as the abscissa and maximum absorbance as the ordinate.

\subsection{Experiments of the Guaiacol and Luffa Degradation}

$10 \mathrm{~mL}$ of $0.75 \mathrm{~g} / \mathrm{L}$ guaiacol-water solution was placed into the plasma reactor. The guaiacol solution was treated under the discharge powder of $100 \mathrm{~W}$. $100 \mathrm{~W}$ was the best discharge power that can be judged by naked eyes. The guaiacol solutions were treated under $5 \mathrm{~min}, 10 \mathrm{~min}, 15 \mathrm{~min}$ and $20 \mathrm{~min}$, respectively. The untreated and plasma-treated guaiacol solutions were diluted during the UV absorbance measurement. The degradation rate $C$ of guaiacol is calculated using Equation (1).

$$
C=\frac{C_{0}-C_{e}}{C_{e}} \times 100 \%
$$

where $C_{0}$ is the concentration of guaiacol solution and $C_{\mathrm{e}}$ is the concentration of guaiacol after plasma treatment, which was calculated according to the standard curve of the guaiacol. 
The experiment of luffa degradation was the same as the process of guaiacol solution. Before the experiment, the luffa is grinded into powders.

\subsection{Preparation of the aPPAC Solvent}

The PPAC solvent composition is defined by the $\mathrm{P}_{2} \mathrm{O}_{5}$ content. PA and PPA correspond to $\mathrm{P}_{2} \mathrm{O}_{5}$ concentration of $72.4 \mathrm{wt} \%$ and $84.0 \mathrm{wt} \%$, respectively. In this experiment, the PPAC solvent was prepared by mixing PA and PPA. The prepared aPPAC solvent was stirred at $30{ }^{\circ} \mathrm{C}$ for $120 \mathrm{~min}$. The mixed PA and PPA solvent had the anhydrous state at $74 \mathrm{wt} \%$ of $\mathrm{P}_{2} \mathrm{O}_{5}$ through the anhydrous $\mathrm{CuSO}_{4}$ powder testing. Then, the aPPAC solvent of $74 \mathrm{wt} \%$ of $\mathrm{P}_{2} \mathrm{O}_{5}$ was prepared.

\subsection{Polarized Optical Microscope Observation}

In observing the dissolution process of the luffa cellulose in the aPPAC solvent, the HPL-85 polarized optical microscope (Shanghai Quantong Optical Co., Ltd., Shanghai, China) was used to trace the dissolution process. The applicable environmental temperature of the HPL- 85 is within 5-35 ${ }^{\circ} \mathrm{C}$. Before the observation, the aPPAC solvent was precooled to $0{ }^{\circ} \mathrm{C}$, and the environmental temperature was adjusted to $5^{\circ} \mathrm{C}$. Then, some extracted luffa cellulose and several drops of the aPPAC solvent were placed on the sample stage. The observation time was from $2 \mathrm{~min}$ to $30 \mathrm{~min}$, and the magnification of the microscope was 100.

\subsection{Preparation of the Regenerated Cellulose Films}

The pretreated luffa cellulose was added into the aPPAC solvent $\left(0{ }^{\circ} \mathrm{C}\right)$ at concentrations of $5 \%$, $10 \%, 15 \%$, and $20 \%$. The luffa cellulose-aPPAC solution was stirred using a magnet stirrer to make it to a homogeneous solution. The stirring time was determined by the results of the polarized optical microscope observation.

The produced luffa cellulose-aPPAC homogeneous solution was placed on a clean glass slide and spread by a smooth glass rod. After spreading the film, the glass slide was quickly immersed into ice water for the $30 \mathrm{~min}$ coagulation. Thereafter, the luffa cellulose films were washed two times to remove the residual solvent, dried at room temperature, and stored in a silica gel dryer. The regeneration of the cellulose film occurred during the coagulation of the film.

\subsection{Characterizations}

The surface morphology of the luffa and luffa cellulose film was observed via a SEM. The samples were coated with gold and examined using the JEOL JSM-6460LV microscope (Tokyo, Japan). The crystalline structure of the untreated luffa and luffa cellulose film was examined using a wide-angle X-ray diffractometer (D/max-3B; Rigaku Co., Ltd., Tokyo, Japan). The samples were scanned from $2 \theta=10-50^{\circ}$ with an operating voltage and current of $40 \mathrm{kV}$ and $200 \mathrm{~mA}$, respectively. The radiation used was Ni-filtered $k \alpha$ radiation with a wavelength of $1.5406 \AA$. The chemical properties of natural luffa and luffa cellulose film were tested via the FTIR (Spectrum One-B; Perkin Elmer Co., Ltd., Waltham, MA, USA). The FTIR spectra were recorded in a scanning range of $400-4000 \mathrm{~cm}^{-1}$ at a resolution of $4 \mathrm{~cm}^{-1}$. The scan speed was $0.2 \mathrm{~cm} / \mathrm{s}$.

The chemical component analysis of the luffa was conducted using the TZ/T 30001-92 "analysis method of ramie fiber chemical composition". The mechanical properties of the regenerated cellulose films were measured using the TH-8102S material testing machine (Suzhou Tuobo Machinery Equipment Co., Ltd., Suzhou, China). The samples were cut into $50 \mathrm{~mm} \times 10 \mathrm{~mm}$ [12], the clamping length was $30 \mathrm{~mm}$, and the stretching speed was $10 \mathrm{~mm} / \mathrm{min}$. Each sample was measured three times to obtain the average value. The polymerization degrees of the cellulose were measured using the copper-ethylenediamine method. The hydrophilicity of the luffa cellulose film was tested using a contact angle meter (K100; Kruss Co., Ltd., Hamburg, Germany). 


\section{Results and Discussion}

\subsection{Evidence of the Radical Produced by Plasma}

In the dielectric barrier discharge, the energetic electrons can collide with the background molecules (e.g., $\mathrm{N}_{2}, \mathrm{O}_{2}$, and $\mathrm{H}_{2} \mathrm{O}$ ) producing secondary electrons, photons, ions, and radicals. Reactive molecular dynamics simulations have been showed that oxygen species of $\mathrm{O}$ atoms, $\mathrm{HO}_{2}$. radicals, $\mathrm{OH}$. radicals, and $\mathrm{H}_{2} \mathrm{O}_{2}$ produced during the energetic electrons colliding with water $[7,8]$.

$\mathrm{CV}$ dye is the indicator of oxidative radicals. The oxidative radicals can oxidize and degrade dyes, lighten their color, and reduce the absorbance value. To prove that the plasma discharge system contains radicals, the CV solution was added into plasma-treated water. Figure 2 shows the spectra of samples (a), (b), and (c). After the reaction of the plasma-treated water with CV, the absorbency peaks of solution (b) remarkably decrease compared with solution (a). This result indicates that oxidative radicals are present in the water produced by the plasma and resulting in the $\mathrm{CV}$ degradation. After pouring the $n$-butyl alcohol, sample (c), the maximum absorbency of the CV solution was $44 \%$, slightly higher than sample b. Given that $n$-butyl alcohol is a free radical trapping agent, the absorbency enhancement also proves that the oxidative radicals are produced in the water. The oxidative radicals are likely one of the $\mathrm{HO}_{2}$.radicals or $\mathrm{OH}$ - radicals or both of them.

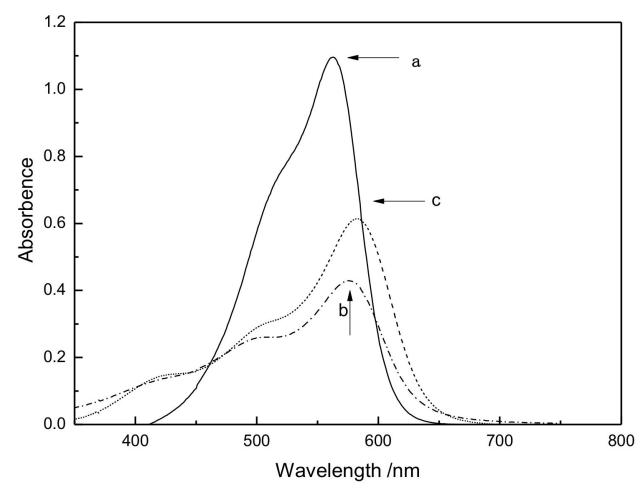

Figure 2. UV spectra of (a) CV solutions;(b) CV solutions with plasma-treated water and (c) CV solutions with plasma-treated water and $n$-butyl alcohol.

In order to determine what type of radicals exist in water, the $\mathrm{pH}$ of the plasma treated water was investigated. The experimental results showed that the plasma-treated water exhibited acidity with the $\mathrm{pH}$ of 3.73. In the free radicals, $\mathrm{HO}_{2} \cdot$ and $\mathrm{OH} \cdot, \mathrm{HO}_{2}$ is a superior proton donor but is a weaker proton acceptor than water [8]. Hence, the result of the $\mathrm{HO}_{2}$ reaction can be expressed in Equation (2). This result indicates that $\mathrm{HO}_{2}$. radicals are present in the plasma treated water. Noticeably, a large number of hydrated protons are produced in water. Yang [13] did an experiment of plasma precipitation of calcium ions in hard water. It was found that alkalinity of water was weakened, indicating the characteristics of plasma acidity in water environment. Note that in Equation (2), with the death of the $\mathrm{HO}_{2}$ free radicals, the reaction will go on in the reverse direction. The concentration of $\mathrm{H}_{3} \mathrm{O}^{+}$will gradually decrease, which resulted in the finally destruction of the acidic water.

$$
\mathrm{HO}_{2} \cdot+\mathrm{H}_{2} \mathrm{O} \leftarrow \rightarrow\left[\mathrm{O}_{2}-\mathrm{H}-\mathrm{OH}_{2}\right] \leftarrow \rightarrow \mathrm{O}_{2}{ }^{-}+\mathrm{H}_{3} \mathrm{O}^{+}
$$

Note that the CV solution or $n$-butyl alcohol was manually poured into the plasma-treated water, thus consuming at least several seconds. Generally, the lifetime of the $\mathrm{OH}$ - radical is a few $\mu$ in a gaseous state. However, apart from $\mathrm{HO}_{2}$. radicals, we detected other radicals in water after the discharge in several seconds in our experiments. It is the $\mathrm{OH}$ - radicals. The theoretically simulated calculation also indicates that the interaction of $\mathrm{OH}$. radicals with water leads to the consecutive formation of another $\mathrm{OH}$. radical [8]. The reaction scheme for $\mathrm{HO}$. in water can be expressed in 
Equation (3). Noticeably, the lifetime of the hydroxyl radicals in water can be a few hundred times greater than that in the gas state.

$$
\mathrm{HO} \cdot+\mathrm{H}_{2} \mathrm{O} \leftarrow \rightarrow[\mathrm{HO}-\mathrm{H}-\mathrm{OH}] \leftarrow \rightarrow \mathrm{H}_{2} \mathrm{O}+\mathrm{HO}
$$

Therefore, it is the $\mathrm{OH}$ - radicals, produced during plasma water discharge, which attack the dye molecules, resulting in the bleaching of the $\mathrm{CV}$ solution. The $\mathrm{OH} \cdot$ and $\mathrm{HO}_{2}$. radical species are evidently produced during the plasma discharge. $\mathrm{HO}$ - can survive longer than the other reactive species in water solution. $\mathrm{HO}_{2}$.reacts with water transformed into $\mathrm{H}_{3} \mathrm{O}^{+}$, thereby enabling the plasma-treated water to produce acidity.

\subsection{Experiment of the Guaiacol Degradation}

Figure 3 is the UV absorbance curves of the guaiacol-water solutions. For all the guaiacol solutions, there are clear absorption peaks at $274 \mathrm{~nm}$, which is attributed to the aromatic ring in the guaiacol molecule. Table 2 lists the absorbance of guaiacol solutions with different concentration at $274 \mathrm{~nm}$. Then the standard curve of guaiacol was drawn. According to the data in Table 2, the linear fitting result of guaiacol concentration-absorbance is $y=0.016 x+0.048$. The correlation coefficient is 0.997 .

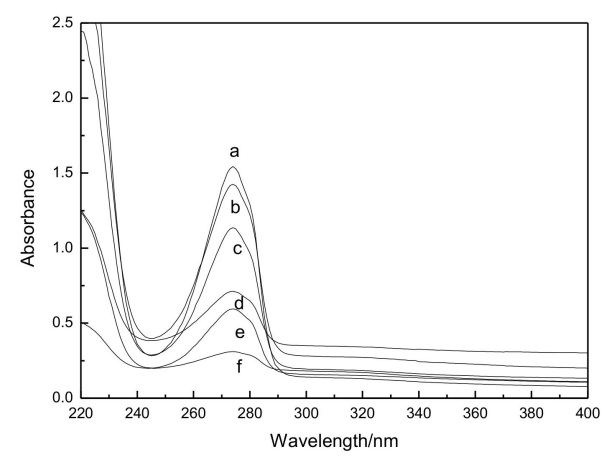

Figure 3. UV absorbance curves of guaiacol-water solutions of (a) $95 \mathrm{mg} / \mathrm{L}$; (b) $80 \mathrm{mg} / \mathrm{L}$; (c) $65 \mathrm{mg} / \mathrm{L}$; (d) $40 \mathrm{mg} / \mathrm{L}$; (e) $35 \mathrm{mg} / \mathrm{L}$ and (f) $15 \mathrm{mg} / \mathrm{L}$.

Table 2. Absorbance of guaiacol solutions.

\begin{tabular}{ccccccc}
\hline NO. & a & b & c & D & e & f \\
\hline Guaiacol solutions (mg/L) & 95 & 80 & 65 & 40 & 35 & 15 \\
Absorbance at 274 nm & 1.581 & 1.399 & 1.132 & 0.711 & 0.598 & 0.300 \\
\hline
\end{tabular}

\subsection{Experiment of the Luffa Degradation}

Figure 4 is the UV absorbance curves of plasma-treated guaiacol-water solutions. For untreated guaiacol solution, in the curve (a), there is a clear absorption peak at $274 \mathrm{~nm}$ of the benzene structural unit in the guaiacol molecular. However, a big change happens in the absorbance curves when the plasma treated time extends to $5 \mathrm{~min}$. A large decreasing of absorption peaks appears at $274 \mathrm{~nm}$. Also, there is a weak absorption peak from $270 \mathrm{~nm}$ to $305 \mathrm{~nm}$. This result indicates that the aromatic rings in the guaiacol are destroyed. Many complexes are produced after the pyrolysis of benzene rings. The produced complexes cause the maximum wavelength red shift and decreases the absorbance. With the increasing of plasma treated time from $10 \mathrm{~min}$ to $20 \mathrm{~min}$, the absorbance at $274 \mathrm{~nm}$ gradually decreases with time. The results show that more benzene rings of guaiacol are destroyed and the guaiacol solution is degraded. Table 3 lists the degradation rate of plasma-treated guaiacol solutions. The degradation rate of guaiacol increases gradually along with the time. After being treated for $20 \mathrm{~min}$, the degradation rate of guaiacol is as high as $80 \%$. 


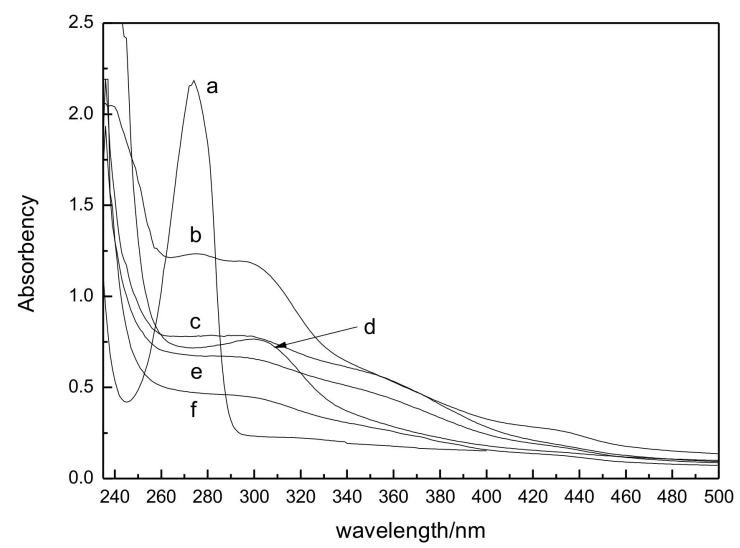

Figure 4. UV absorbance curves of plasma-treated solutions at (a) $0 \mathrm{~min}$; (b) $5 \mathrm{~min}$; (c) $10 \mathrm{~min}$; (e) $15 \mathrm{~min}$ and (f) $20 \mathrm{~min}$ and luffa at (d) $20 \mathrm{~min}$.

Table 3. Degradation rate of plasma-treated guaiacol solutions.

\begin{tabular}{ccccc}
\hline No. & Samples & Time (min) & Absorbance at 274 nm & Degradation Rate (\%) \\
\hline a & guaiacol & 0 & 2.182 & $/$ \\
b & guaiacol & 5 & 1.235 & 44 \\
c & guaiacol & 10 & 0.774 & 66 \\
d & luffa & 20 & 0.710 & 69 \\
e & guaiacol & 15 & 0.652 & $/$ \\
f & guaiacol & 20 & 0.485 & 80 \\
\hline
\end{tabular}

During the plasma discharge of water, a large number of $\mathrm{OH} \cdot$ and $\mathrm{HO}_{2}$. radicals are produced, which has been proved by the above experiments. On the one hand, these oxidative radicals will attack benzene rings and form benzene radicals. Benzene radicals can capture other free radicals to produce biphenyl compounds. On the other hand, The $\mathrm{C}=\mathrm{C}$ of benzene and biphenyl compounds can be further oxidized and destroyed. Many complexes with one or more functional groups, such as carbonyl groups, carboxyl groups, and among many others, are produced. These compounds can continue to be degraded into small molecule such as $\mathrm{CO}_{2}, \mathrm{H}_{2} \mathrm{O}$, etc. This can be explained the result of a weak absorption peak at 270-305 $\mathrm{nm}$.

\subsection{Experiment of the Luffa Degradation}

The $\mathrm{OH} \cdot$ and $\mathrm{H}_{3} \mathrm{O}^{+}$reactive species are therefore produced during the plasma discharge of water. The oxidative radicals are useful in eliminating lignin whereas $\mathrm{H}_{3} \mathrm{O}^{+}$in eliminating hemicellulose, pectin, and other non associated substances in the luffa raw material. Then the degradation of luffa was carried out with a discharge time of $20 \mathrm{~min}$ and plasma power of $100 \mathrm{~W}$. Based on the $8.1 \%$ lignin content in the luffa fiber presented in Table 4 , and the treated guaiacol of $0.75 \mathrm{~g} / \mathrm{L}$, the estimated luffa powder concentration was $9.26 \mathrm{~g} / \mathrm{L}$.

Table 4. Main components of untreated and plasma-treated luffa fibers.

\begin{tabular}{cccc}
\hline & Hemicellulose & Lignin & Cellulose \\
\hline Untreated $(\%)$ & 20.1 & 14.5 & 65.4 \\
Plasma treated $(\%)$ & 10.7 & 8.1 & 81.2 \\
\hline
\end{tabular}

After plasma treatment, the cellulose content of luffa fiber increases to $81.2 \%$ and the hemicellulose and lignin contents decrease. The results show that the removed rate of lignin is approximately $45 \%$. However, using the chemical method [14], treatment was carried out by steeping the luffa in $2 \% \mathrm{NaOH}$ 
for $90 \mathrm{~min}$ or $1 \%$ methacrylamide aqueous solutions for $180 \mathrm{~min}$. The lignin removal rate of these treatments was $27 \%$ and $7 \%$, respectively. Thus, the lignin removal is more effective in this study.

Figure $4 \mathrm{~d}$ is the UV absorbance of residue of plasma-treated luffa. There are also nonclear absorption peaks at $274 \mathrm{~nm}$, indicating that the benzene structure of lignin is destroyed. Note that there is an obvious and broad absorption peak at $310 \mathrm{~nm}$. It is very different from the curve of plasma-treated guaiacol solutions. As is well known, the chemical structure of natural lignin is more complex than guaiacol. Particularly, in the gramineous plants, the lignin contains a certain amount of phenyl-coumarin structure. The phenyl-coumarin structure will be dehydrated to phenyl-coumarone at the acidic conditions. Phenyl-coumarone has a clear absorption peak at $310 \mathrm{~nm}$. Then the clear absorption peak of $310 \mathrm{~nm}$ is attributed to the phenyl-coumarone of luffa. In addition to the complexes with carbonyl, carboxyl, etc., the complexes with ketone group are produced after the destruction of lignin. Meanwhile, this result gives indirect evidence that plasma-treated water is a kind of acidic water.

In this study, the energy consumption of luffa degradation is $120 \mathrm{~kJ}$ per $9.26 \mathrm{~g}, 13 \mathrm{~kJ}$ per gram luffa powder. It is a little higher than the electrical energy consumption of a ramie degumming factory in China. This is a major problem in plasma treatment. The biggest advantage of this method is the post-treatment of degumming residues. It is simple and environmentally friendly for no chemicals to be used in the degumming process. Moreover, as time went by the acidity of the plasma treated water would fade gradually [15]. It is great benefit for the recycling of water and has important significance for energy saving and for decreasing air pollution. The reason for acidic water turning into neutral water has been clarified in Equation (2). Then, it is concluded that plasma treatment is an environmentally friendly and high-efficiency method for luffa degumming. The degumming experiments of other materials, such as hemp and ramie, are now performed.

\subsection{SEM of the Luffa by Plasma Treatment}

Figure 5 presents SEM micrographs of the surface morphology of the untreated and pretreated luffa. As presented in (a) and (c), it can be seen that the fibers show a homogeneous aspect, with a rough surface and an outer lignin rich layer around the fiber. Most of the fibrils of the untreated luffa fibers are glued together, thereby forming a thick fiber with a diameter of approximately 100-150 $\mu \mathrm{m}$. The internal fibrils are not observed. However, as showed in (b) and (d), the plasma-treated luffa fibers display an irregular surface. The formation of surface indentations can be seen clearly. They are the results of plasma treatment due to a great level of surface material being removed. Figure $5 \mathrm{e}$ is the cross section of the untreated luffa. The SEM image shows the complicated physical structure in the natural luffa, which forms a natural, porous mat, similar in structure to that of a sponge. As presented in (f), in the cross section of plasma-treated luffa, a permanent damage of fiber integrity is more evident. There are many pores and gaps in the fractured surface, which consequently increase the exposing opportunity of the fiber inner layers to solvent. Thus, the dissolution of luffa cellulose in the solvent becomes easy and the dissolution rate of luffa cellulose will be enhanced.

It is interesting to note that plasma treatment leaves the bulk single fiber intact and only modifies the outer surface layers. This feature may improve the interfacial phenomena when the obtained luffa fibers are used as absorption materials, filters, and in polymeric composites. Moreover, this is similar to the result that Tanobe et al. [14] had reported for luffa fibers treated by $\mathrm{NaOH}$ and methacrylamide. Thus, compared with the chemical pretreatment, it is concluded that plasma treatments greatly reduce the treatment time and do not require the use of solvent. 


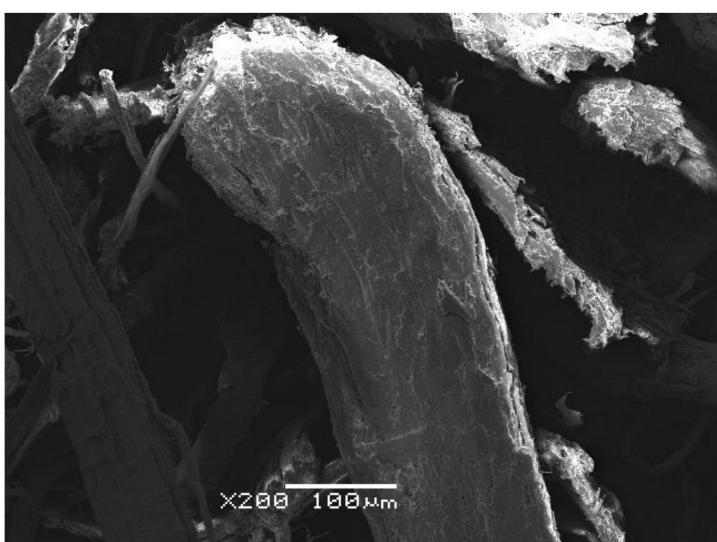

(a)

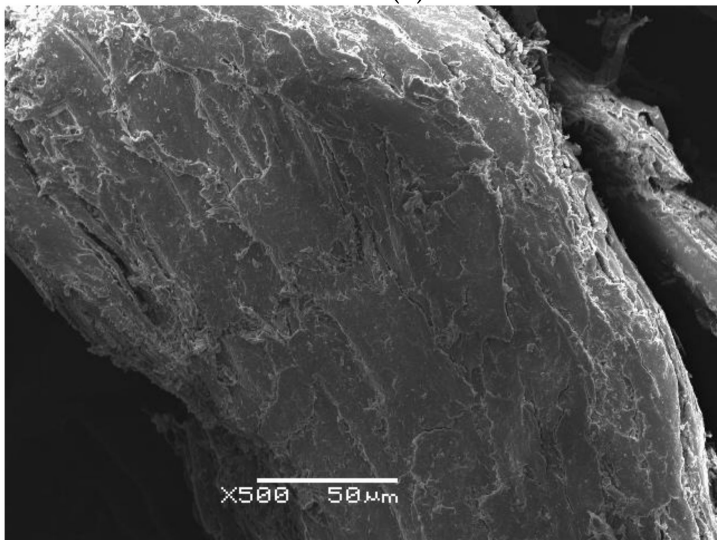

(c)

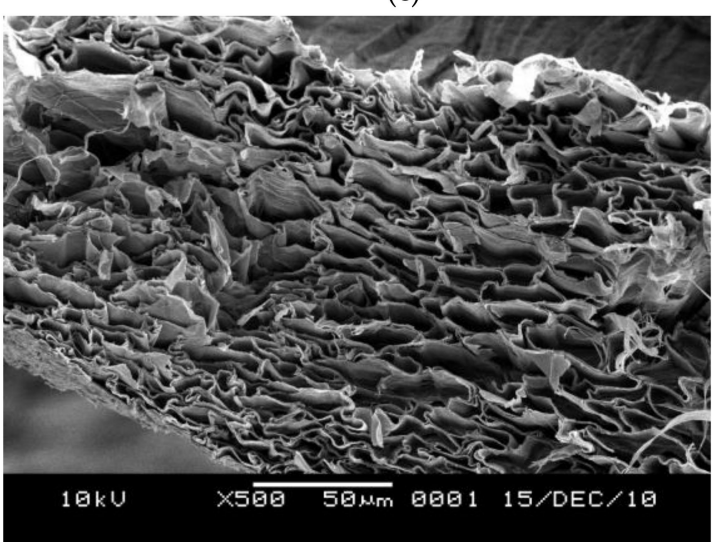

(e)

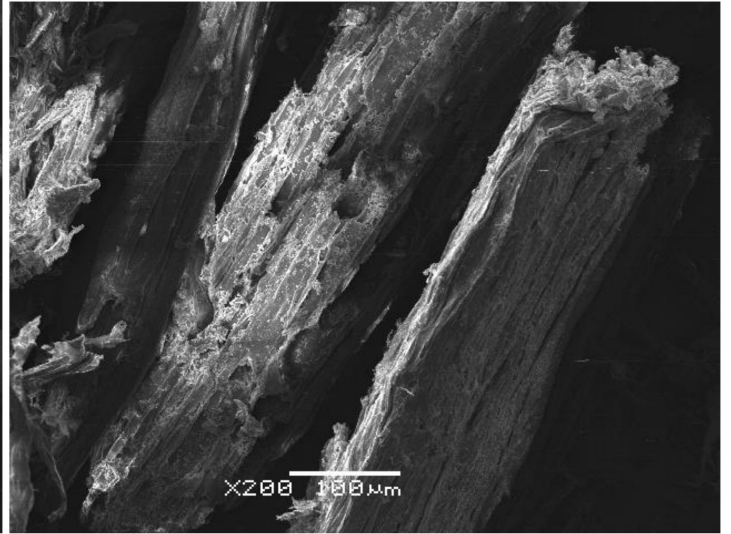

(b)

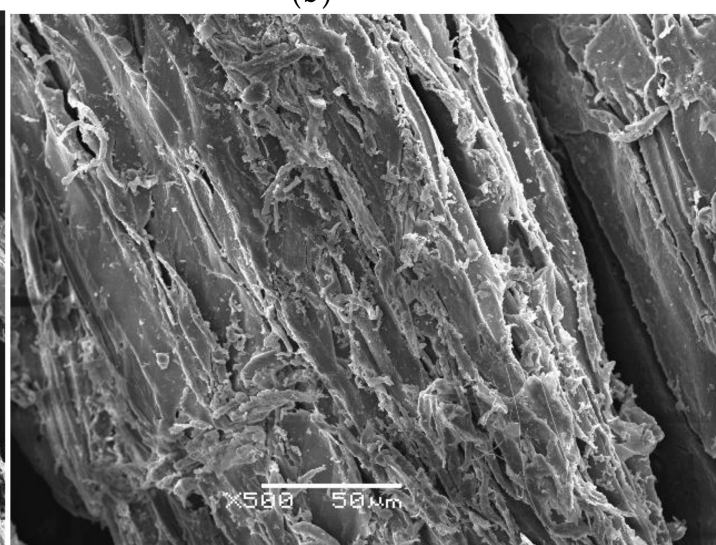

(d)

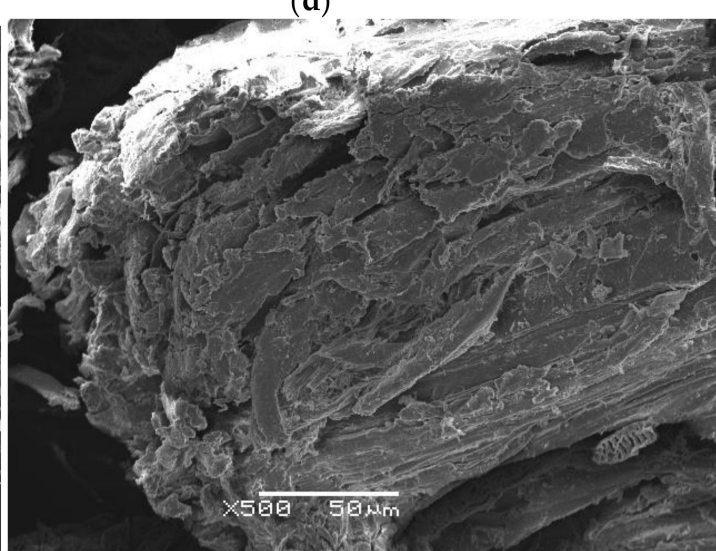

(f)

Figure 5. SEM images of (a) untreated luffa at $200 \times$ magnification; (b) plasma-treated luffa at $200 \times$ magnification; (c)untreated luffa at 500 $\times$ magnification; (d) plasma-treated luffa at 500 $\times$ magnification; (e) cross section of untreated luffa at $500 \times$ magnification and (f) cross section of plasma-treated luffa at $500 \times$ magnification.

\subsection{Polarized Optical Microscope Observation}

By using the polarized optical microscope, one can see the molecular orientation of the cellulose. If the cellulose structure disappears in the optical microscope during the dissolution process, then the cellulose has been dissolved completely in the solvent. The images of the pretreated luffa dissolving in the aPPAC solvent obtained from the polarized optical microscope are shown in Figure 6a-d. The figures illustrate the dissolution process of the luffa cellulose in the aPPAC solvent.

A large number of clubbed luffa fibrils appear in the aPPAC solvent in $2 \mathrm{~min}$. Meanwhile, the number of luffa fibrils clearly decrease in $10 \mathrm{~min}$. After $15 \mathrm{~min}$, only a few fibrils are observed. When the 
dissolution continues up to $25 \mathrm{~min}$, nothing is visible in the optical photograph. Hence, the fibrils are completely dissolved in the aPPAC solvent. The reaction between $\mathrm{H}_{4} \mathrm{PO}_{4}{ }^{+}$and the hydroxyl groups on cellulose chains leads to cellulose dissolution in the aPPAC solvent. Therefore, the dissolution time of the extracted luffa cellulose in the aPPAC solvent was $25 \mathrm{~min}$ within the circumstance temperatures of $0-5^{\circ} \mathrm{C}$. Subsequently, the luffa cellulose-aPPAC solution was prepared for stirring for $25 \mathrm{~min}$.

Compared with the NMMO cellulose dissolution system of more than 8-10 h at 80-100 ${ }^{\circ} \mathrm{C}$ [9], the dissolution time of the cellulose in the aPPAC solvent is faster, and the dissolution temperature is lower. Within a temperature of $0-5{ }^{\circ} \mathrm{C}$, only 25 minis required for the cellulose to dissolve.

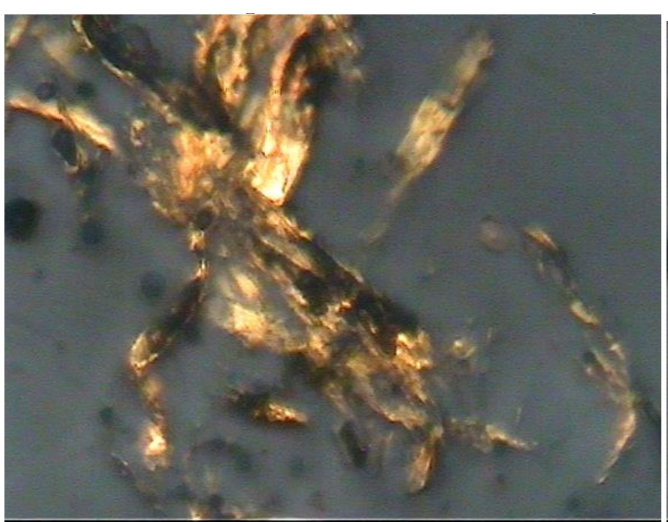

(a)

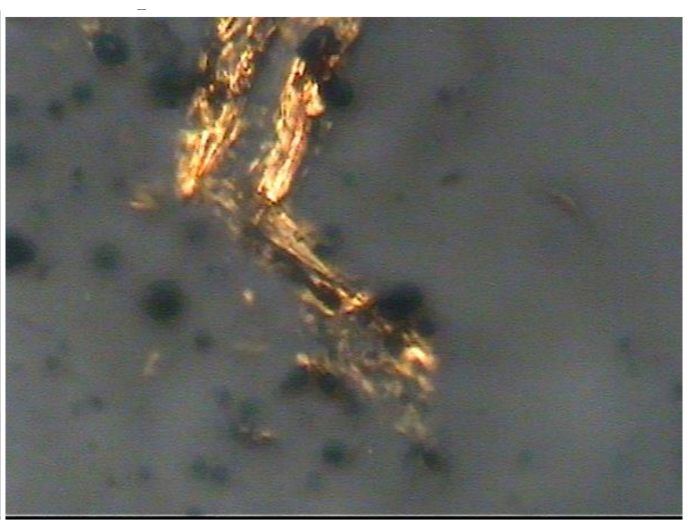

(b)

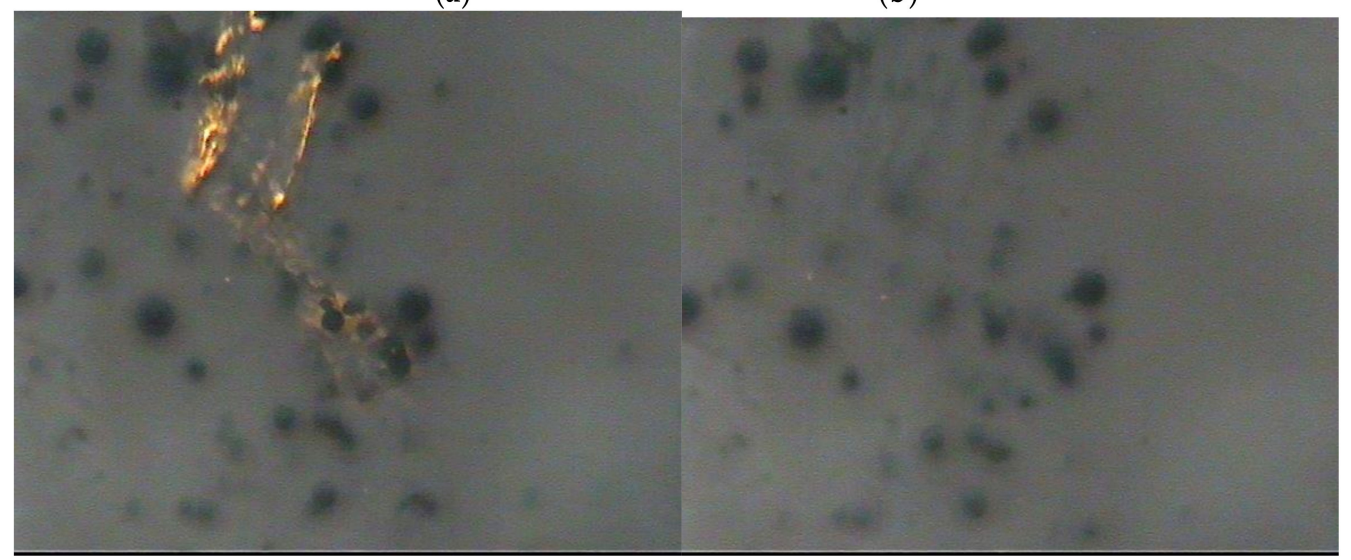

(c)

(d)

Figure 6. Dissolution process of luffa cellulose in the aPPAC solvent at (a) $2 \mathrm{~min}$; (b) $10 \mathrm{~min}$; (c) $15 \mathrm{~min}$ and (d) $25 \mathrm{~min}$.

\subsection{Preparation of the Luffa Cellulose-aPPAC Film}

Based on the polarized optical microscope results, the luffa cellulose-aPPAC solutions were prepared at $25 \mathrm{~min}$ and $0{ }^{\circ} \mathrm{C}$, with concentration of $5 \%, 10 \%, 15 \%$, and $20 \%$, respectively. For the $5 \%$ concentration, a smaller cellulose chain was observed in the solution, resulting in a low viscosity of the solution. For higher concentration of up to $20 \%$, many molecular chains would increase the viscosity of the solution. Preparing a film both in a higher and lower viscosity is difficult. Thus, we only used a $15 \%$ solution in this study. The regenerated luffa cellulose film was prepared by casting the luffa cellulose-aPPAC solution $\left(15 \%, 25 \mathrm{~min}\right.$, and $\left.0{ }^{\circ} \mathrm{C}\right)$ in ice water for $30 \mathrm{~min}$ of coagulation.

\subsection{XRD Analysisof the Luffa Cellulose-aPPAC Film}

Figure 7 shows the XRD spectra of the untreated luffa fibers and regenerated luffa cellulose films. The characteristic peaks of the untreated luffa fibers appear at $2 \theta=15.7^{\circ}, 22.4^{\circ}$, and $34.4^{\circ}$, thereby matching with cellulose I. Meanwhile, the main peaks of the regenerated luffa cellulose films are 
presented at $2 \theta=11.9^{\circ}$ and $21.5^{\circ}$, thereby matching with cellulose II. Therefore, the original lattice of the luffa is altered under the action of the aPPAC solvent.

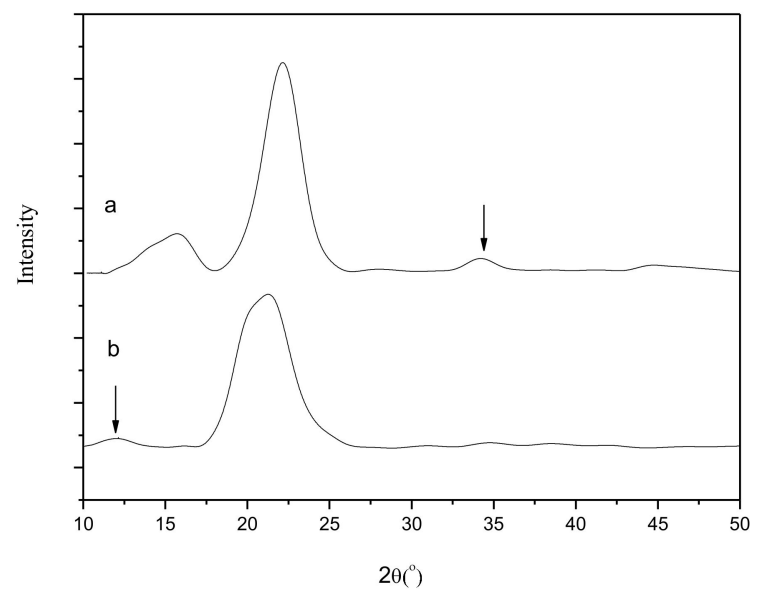

Figure 7. XRD spectra of (a) untreated luffa and (b) regenerated luffa cellulose film.

\subsection{FTIR Analysis of the Luffa Cellulose-aPPAC Film}

The chemical structure of luffa fibers and regenerated luffa cellulose films was characterized by FTIR. Figure 8 shows the FTIR spectra, and Table 5 specifies the observed absorptions. The untreated luffa in curve a shows the intense, characteristic peaks of the lignocelluloses materials at approximately $3360 \mathrm{~cm}^{-1}$ (O-H stretching band), $2900 \mathrm{~cm}^{-1}$ (CH stretching band), $1750 \mathrm{~cm}^{-1}$ (C-O stretching band), $1646 \mathrm{~cm}^{-1}$ (O-H deformation band), $1429 \mathrm{~cm}^{-1}$ and $1062 \mathrm{~cm}^{-1}$ (characteristic peaks related to the cellulose), and $1500 \mathrm{~cm}^{-1}$ and $1469 \mathrm{~cm}^{-1}$ (characteristic peaks related to lignin).

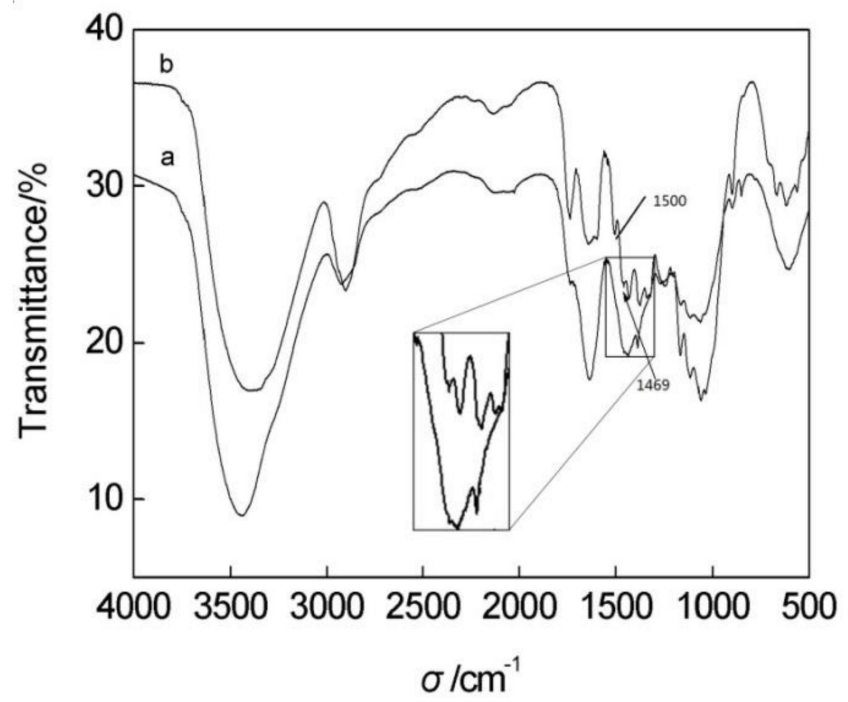

Figure 8. FTIR spectra of (a) regenerated luffa cellulose film and (b) untreated luffa fiber.

After the regeneration process shown in curve $b$, the film shows the strong characteristic peaks related to the cellulose and no new functional groups were produced. One of the alterations in the regeneration process is that the cellulose in film does not show the absorption peaks at $1469 \mathrm{~cm}^{-1}$ and $1500 \mathrm{~cm}^{-1}$. The disappearance of these two peaks is due to the removal of lignin by the destruction of benzene rings. Obviously, there is a band of $\mathrm{C}=\mathrm{O}$ at $1750 \mathrm{~cm}^{-1}$, which has a lower intensity as that in curve a. Probably, it is the by-product of lignin degradation, complexes with carbonyl, carboxyl, ketone group, and the like. Of course, itis also a possibility for the exposure of inner lignin, or for both of them together. 
Evidently, part of lignin has been removed by the plasma pretreatment. No significant differences between the chemical structure of the untreated luffa and luffa cellulose film were found. Moreover, the derivatization reaction does not occur during the regeneration process of the luffa cellulose in films. Removal of all lignin in its native state from the fibrils remains a problem for further investigation.

Table 5. Peak positions of untreated and regenerated luffa cellulose film.

\begin{tabular}{ccc}
\hline \multicolumn{2}{c}{ Wavenumbers $\mathbf{( c m}^{-\mathbf{1}} \mathbf{)}$} & Assignments \\
\cline { 1 - 2 } $\mathbf{a}$ & $\mathbf{B}$ & OH stretching \\
3360 & 3360 & Saturated C-H stretching \\
2900 & 2900 & C=O stretching of acetyl or carboxylic acid \\
1750 & 1750 & OH deforming \\
1646 & 1646 & Aromatic bending C-H (lignin) \\
1500 & - & Aromatic methyl group stretching(lignin) \\
1469 & - & CH $_{2}$ scissoring (cellulose) \\
1429 & 1420 & C-OR stretching (cellulose) \\
1062 & 1055 &
\end{tabular}

\subsection{SEM Analysis of the Luffa Cellulose-aPPAC Film}

As shown in the cross section presented in Figure 9, the surface of the film is not very smooth at $3000 \times$ magnification. The roughness surface probably is formed in the coagulation bath. The surface of the film coagulated rapidly. But the inside of the film coagulated slowly. No big cellulose particles appeared and few voids appeared in the cross-section, indicating that the luffa cellulose has completely dissolved in the aPPAC solvent and a compact film is obtained.

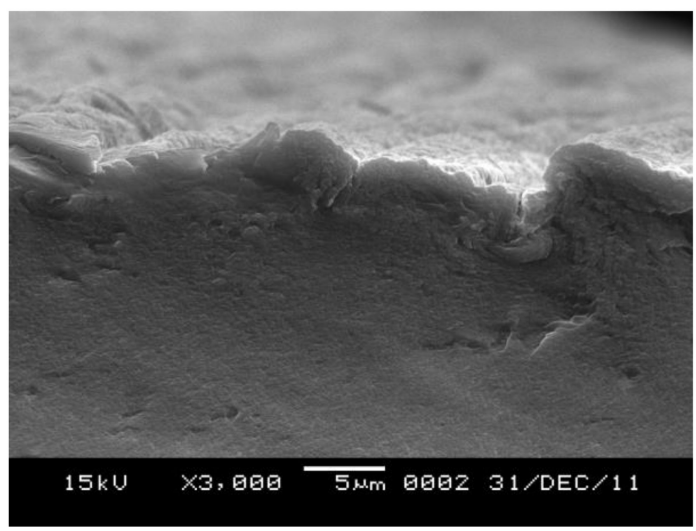

Figure 9. SEM of cross section of the regenerated luffa film.

\subsection{Mechanical Properties and Contact Angle Measurement of the Regenerated Cellulose Films}

The breaking strength of the regenerated cellulose films was $36.78 \mathrm{MPa}$, the breaking elongation of the films was $31.55 \%$, and the polymerization degree of the cellulose of the dried luffa was 714 . After the treatment, the polymerization degree of the luffa cellulose became 564. The contact angle measurements of the regenerated luffa cellulose films are listed in Table 6. The average contact angle of the cellulose film was $16.38^{\circ}$. The result demonstrates that the films exhibit good mechanical properties and wettability.

Table 6. Contact angle of the regenerated luffa cellulose film.

\begin{tabular}{cc}
\hline No. & Contact Angle $\left.{ }^{\circ}{ }^{\circ}\right)$ \\
\hline 1 & 16.45 \\
2 & 15.28 \\
3 & 17.42 \\
The average value & 16.38 \\
\hline
\end{tabular}




\section{Conclusions}

In this study, guaiacol was used as the model compound to investigate the degradation of lignin in luffa. The evidence of the oxidative radical produced by plasma was done. The results showed that the $\mathrm{OH} \cdot$ and $\mathrm{H}_{3} \mathrm{O}^{+}$reactive species were evidently produced during plasma discharge. The free radical $\cdot \mathrm{OH}$ was useful in eliminating lignin by the destruction of aromatic structure, whereas $\mathrm{H}_{3} \mathrm{O}^{+}$in eliminating hemicellulose in the luffa raw material.

The new cellulose material was extracted from natural luffa by a pretreatment based on the oxidation and acidity of glow discharge plasma in water. With the conditions of powder concentration of $9.26 \mathrm{~g} / \mathrm{L}$, discharge time of $20 \mathrm{~min}$, and plasma power of $100 \mathrm{~W}$, the component of the cellulose was increased to $81.2 \%$. Part of lignin had been removed by the plasma pretreatment for the destruction of lignin. The destroyed results of luffa lignin were the complexes with carbonyl, carboxyl, ketone group, and the like.

The luffa cellulose-aPPAC dissolution system was also investigated. The results showed that the aPPAC solvent was a good non-derivatizing solvent for the luffa cellulose, and the anhydrous state of the PPAC was achieved at $74 \mathrm{wt} \%$ of $\mathrm{P}_{2} \mathrm{O}_{5}$ concentrations. The luffa cellulose completely dissolved in the aPPAC solvent at $0{ }^{\circ} \mathrm{C}$ and $25 \mathrm{~min}$ for a $15 \%$ solution.

The regenerated luffa cellulose film was successfully prepared by casting the luffa cellulose-aPPAC solution in ice water for $30 \mathrm{~min}$ coagulation. After being regenerated in films, the crystalline structures of the luffa cellulose film were transformed from cellulose I to cellulose II. The luffa cellulose film appeared the characteristic functional groups related to the cellulose. No derivatization reaction occurred during the dissolution process. The films also exhibited good mechanical properties, wettability and a compact structure.

Therefore, a new cellulose material was extracted from natural luffa by a pretreatment based on the oxidation and acidity of glow discharge plasma in water. This was an environmentally friendly and high-efficiency method for luffa degumming. The biggest advantage of this method is the simple and environmentally friendly post-treatment of residues. Moreover, luffa cellulose is a new source suitable in producing regenerated cellulose films. Further investigations on crystallinity and the penetration properties of luffa cellulose films are ongoing.

Author Contributions: Y.W. conceived and designed the experiments. Z.-x.D. and Z.-c.X. performed the experiments. Y.-h.Z. and C.-y.W. analyzed the data. Y.W. and Z.-x.D. wrote the paper.

Funding: This study was supported by Liaoning Province Natural Science Foundation [grant number 20170540064], China.

Conflicts of Interest: The authors declare no conflict of interest.

\section{References}

1. Porterfield, W.M. Loofah-the sponge gourd. Econ. Bot. 1955, 9, 211-223. [CrossRef]

2. Boynare, C.A.; D'almeida, J.R.M. Morphological characterization and mechanical behavior of sponge gourd (Luffa-cylindrica)-polyester composite materials. Polym. Plast. Technol. Eng. 2010, 39, 489-499. [CrossRef]

3. Demir, H.; Top, A.; Balköse, D.S.; Ülkü, S. Dye adsorption behavior of Luffa cylindrica fibers. J. Hazard. Mater. 2008, 153, 389-394. [CrossRef] [PubMed]

4. Ghali, L.; Msahli, S.; Zidi, M. Effect of pre-treatment of luffa fibers on the structural properties. Mater. Lett. 2009, 63, 61-63. [CrossRef]

5. Ostrikov, K.; Neyts, E.C.; Meyyappan, M. Plasma nanoscience: From nano-solid in plasmas to nano-plasmas in solids. Adv. Phys. 2013, 62, 113-224. [CrossRef]

6. Yousfi, M.; Merbahi, N.; Pathak, A.; Eichwald, O. Low-temperature plasmas at atmosphere pressure: Toward new pharmaceutical treatments in medicine. Fundam. Chin. Pharmacol. 2013, 27, 1-13.

7. Joshi, A.A.; Locke, B.R.; Arce, P.; Finne, W.C. Formation of hydroxyl radicals, hydrogen peroxide and aqueous Electrons by pulsed streamer corona discharge in aqueous Solution. J. Hazard. Mater. 1995, 41, 3-30. [CrossRef] 
8. Yusupov, M.; Neyts, E.C.; Simon, P.; Berdiyorov, G.; Snoeckx, R.; van Duin, A.C.T.; Bogaerts, A. Reactive molecular dynamics simulations of oxygen species in a liquid water layer of interest for plasma medicine. J. Phys. D Appl. Phys. 2014, 47, 05205. [CrossRef]

9. Fadeeva, J.A.; Shmuklert, L.E.; Safonova, L.P. Investigation of the phosphoric acid-N,N-dimethyformamide system as potential solvent for cellulose. Thermochim. Acta 2003, 405, 117-123. [CrossRef]

10. Wang, Y.; Ji, Y.C.; Wei, L.; Wang, Q.H.; Li, H. Dissolution and regeneration in films of natural luffa in1-butyl-3-methylimidazolium chloride. J. Macromol. Sci. Phys. 2015, 54, 571-580. [CrossRef]

11. Li, N.; Xiong, R.; Li, F.X.; Yu, J.Y.; Hu, P.P.; Liu, Z.F. The structure development of cellulose dissolved in the phosphoric acid/polyphosphoric acid solvent. J. Donghua Univ. 2011, 28, 485-487.

12. Huang, Z.M.; Zhang, Y.Z.; Ramakrishna, S.; Lim, C.T. Electrospinning and mechanical characterization of gelatin nanofibers. Polymer 2004, 45, 5361-5368. [CrossRef]

13. Yong, Y.; Hyoungsup, K.; Andrey, S.; Young, C.; Alexander, F. Mechanism of calcium ion precipitation from hard water using pulsed spark discharges. Plasma Chem. Plasma Process. 2011, 31, 51-66. [CrossRef]

14. Valcineide, O.A.; Thais, H.D.; Marilda, M.; Sandro, C.A. A comprehensive characterization of chemically treated Braziliansponge-gourds (Luffa cylindrica). Polym. Test. 2005, 24, 474-482.

15. Wang, Y.; Yuan, B.; Ji, Y.C.; Li, H. Hydrolysis of hemicellulose to produce fermentable monosaccharides. Carbohydr. Polym. 2013, 97, 518-522. [CrossRef] [PubMed]

(C) 2018 by the authors. Licensee MDPI, Basel, Switzerland. This article is an open access article distributed under the terms and conditions of the Creative Commons Attribution (CC BY) license (http://creativecommons.org/licenses/by/4.0/). 